\title{
Transcriptome analysis of Auricularia fibrillifera fruit-body responses to drought stress and rehydration
}

\author{
Yiqin Wang ${ }^{\dagger}$, Zhifen Yang ${ }^{\dagger}$, Luxi Shi, Rui Yang, Hao Guo, Suqin Zhang ${ }^{*}$ and Guangdong Geng*
}

\begin{abstract}
Background: Drought stress severely restricts edible fungus production. The genus Auricularia has a rare drought tolerance, a rehydration capability, and is nutrient rich.

Results: The key genes and metabolic pathways involved in drought-stress and rehydration were investigated using a transcriptome analysis to clarify the relevant molecular mechanisms. In total, $173.93 \mathrm{Mb}$ clean reads, $26.09 \mathrm{~Gb}$ of data bulk, and 52,954 unigenes were obtained. Under drought-stress and rehydration conditions, 14,235 and 8539 differentially expressed genes, respectively, were detected. 'Tyrosine metabolic,'caffeine metabolism', 'ribosome,' 'phagosome', and 'proline and arginine metabolism', as well as 'peroxisome' and 'mitogen-activated protein kinase signaling' pathways, had major roles in A. fibrillifera responses to drought stress. 'Tyrosine' and 'caffeine metabolism' might reveal unknown mechanisms for the antioxidation of $A$. fibrillifera under drought-stress conditions. During the rehydration process, 'diterpenoid biosynthesis,' 'butanoate metabolism,' ' $C_{5}$-branched dibasic acid', and 'aflatoxin biosynthesis' pathways were significantly enriched. Gibberellins and $\gamma$-aminobutyric acid were important in the recovery of $A$. fibrillifera growth after rehydration. Many genes related to antibiotics, vitamins, and other health-related ingredients were found in A. fibrillifera.
\end{abstract}

Conclusion: These findings suggested that the candidate genes and metabolites involved in crucial biological pathways might regulate the drought tolerance or rehydration of Auricularia, shedding light on the corresponding mechanisms and providing new potential targets for the breeding and cultivation of drought-tolerant fungi.

Keywords: Auricularia fibrillifera, Transcriptome analysis, Drought stress, Rehydration, Melanin, Caffeine, Gibberellin, $\gamma$-aminobutyric acid

\section{Introduction}

Drought is a severe environmental stress that negatively effects vegetative growth. The growth and yield of common organisms, including most edible fungi and terrestrial plants, suffer irrecoverable damage as a result of serious drought stress. Büntgen et al. (2015) found that the fruit body number of edible mushrooms, including Boletus edulis and Lactarius spp., decreased by three

\footnotetext{
*Correspondence: zsqin2002@163.com; genggd213@163.com

†Yiqin Wang and Zhifen Yang contributed equally to this work.

College of Agriculture, Guizhou University, Guiyang, Guizhou, China
}

times due to the dry season period. In addition, the overall weight of fruit bodies has also declined since 1995, with a drop of nearly 10 tons [1].

Drought triggers organismal responses, including signal transduction, gene expression regulation, respiration enhancement, osmoprotectant and antioxidant enzyme accumulation, and growth inhibition [2]. Excessive reactive oxygen species (ROS) are produced under droughtstress conditions, thereby affecting redox homeostasis and producing oxidative stress, as evidenced by severe cellular damage as a result of peroxidation, reduced cell membrane stability, and increased protein denaturation 
[3-5]. The antioxidant systems that regulate ROS levels consist of both enzymatic, such as catalase (CAT), glutathione reductase, and peroxidase (POD), and nonenzymatic, such as ascorbate, glutathione, and ROS scavengers [6, 7]. Osmotic adjustment and cellular compatible solute accumulation are widely recognized to have roles in plant adaptation to dehydration, mainly through turgor maintenance and the protection of specific cellular functions by defined solutes [8]. A high proline content in pepper increases the leaf water content and reduces oxidative damage [9]. As the drought-stress level increases, the contents of proline and other osmolytes increase, which helps maintain the relative water content in corn plants [10].

Next-generation sequencing technologies provide high-throughput resources for gene expression profiling at the whole-genome level [11, 12]. Transcriptome analyses provide deep insights into global expression profiles under stress conditions, and they reveal valuable information about the responses of organisms to abiotic stresses [13-15]. At present, transcriptome technology has been used in the lichen-forming fungus Endocarpon pusillum [16], as well as melanized fungi [17], Arbuscular mycorrhizal fungi [18], Piriformospora indica [19], Arabidopsis [20], chickpea [21], cucumber [22], and rice [23, $24]$, to analyze the molecular responses to drought stress and elucidate drought-related adaptive mechanisms. The lichen-forming fungus isolated from the desert lichen $E$. pusillum is extremely drought resistant. Some pathways participate in the drought response in E. pusillum; the genes associated with calcium-mediated and 'mitogenactivated protein kinase (MAPK) signaling' pathways were differentially expressed, and are worthy of further investigation [16]. Arbuscular mycorrhization may possibly affect the adjustment capacity of common bean during water scarcity events. Chickpea produces 1624 differentially expressed genes (DEGs) under droughtstress conditions, such as putative mannitol dehydrogenase, serine hydroxymethyltransferase 4-like, heat shock protein-like, cytochrome P450 81E8-like, and galactinolsucrose galactosyltransferase-like genes, which would be helpful for the investigation of candidate genes responsible for chickpea drought tolerance [25]. In drought-tolerant maize inbred seedlings, the DEGs related to amino acid biosynthesis, stress signal transduction, carbohydrate synthesis, and cell-wall remodeling, as well as the transcription factors play key roles in drought tolerance [26]. After treating Amorpha fruticosa seedlings with PEG-6000, most DEGs were up-regulated, and 'cell wall', 'signal transduction', and 'hormonal regulation-related' pathways were functionally enriched [27]. Auricularia is an extensively cultivated mushroom worldwide owing to its high nutritional, economic, and medicinal values
[28]. It has anti-tumor, anti-inflammatory, hypoglycemic, hypolipidemic, cholesterol-lowering, and immunomodulatory properties [29-33]. The fruit bodies of Auricularia become dry and enter dormancy under drought-stress conditions. Once watered, dormancy is broken. The viability of Auricularia is rare in the eukaryotic community under arid conditions. Thus, the rare drought tolerance and rehydration capability of Auricularia make it an ideal species to explore adaptive mechanisms against drought stress [34].

In recent years, most studies on Auricularia auriculajudae have focused on the genetic diversity, taxonomy [35], laccase-related genes [28], medicinal properties [36-38], extraction techniques of polysaccharides [39, 40], and the mechanism of melanin accumulation under freezing conditions [41]. Auricularia fibrillifera has a rare drought tolerance and rehydration capability. At present, there are limited reports on transcriptome analyses of the responses to drought stress and rehydration in A. fibrillifera. Here, the key genes and metabolic pathways under drought-stress and rehydration conditions were investigated through a transcriptome analysis of A. fibrillifera fruiting bodies. The objectives were to understand the molecular response patterns under drought-stress and rehydration conditions, and to clarify the molecular mechanisms involved in drought tolerance and rehydration. The results provide a valuable reference for Auricularia breeding and its cultivation.

\section{Results}

\section{Overview of the transcriptomic responses to drought stress and rehydration}

A total of 12 cDNA libraries (two treatments and two controls with three replicates of each) were constructed using equal amounts of RNA extracted from the fruit bodies of $A$. fibrillifera under both drought-stress and rehydration conditions. We obtained $173.93 \mathrm{Mb}$ clean reads and $26.09 \mathrm{~Gb}$ of data bulk, with an average GC content of $60.60 \%$ (Table 1). Then, 52,954 unigenes were

Table 1 Sequence statistics of the A. fibrillifera transcriptome

\begin{tabular}{ll}
\hline Total number of unigenes & $\mathbf{5 2 , 9 5 4}$ \\
\hline Total clean reads (Mb) & 173.93 \\
Total clean bases (Gb) & 26.09 \\
Average GC content (\%) & 60.60 \\
Total nucleotides of unigenes (bp) & $59,611,528$ \\
Mean length of unigenes (bp) & 1125 \\
Largest unigenes (bp) & 45,246 \\
Smallest unigenes (bp) & 200 \\
Scaffold N50 size (bp) & 1743 \\
\hline
\end{tabular}


generated from assembled high-quality reads, which encompassed 59,611,528 nucleotides. The unigene length ranged from 200 to $45,246 \mathrm{bp}$, with an average of $1125 \mathrm{bp}$ and a scaffold N50 size of $1743 \mathrm{bp}$. Among these unigenes, 42.22, 15.31, and 5.79\% were longer than 1000 , 2000, and 3000 bp, respectively (Supplementary Fig. S1).

Using BlastX, the unigene sequences were annotated through searches against the public databases. A total of 52,954 unigenes had homologs in at least one of the public databases, including Non-redundant protein sequence database (NR), NCBI non-redundant nucleotide sequences (NT), Swiss-Prot protein sequence database (SwissProt), Eukaryotic Orthologous Groups (KOG), Kyoto Encyclopedia of Genes and Genomes (KEGG), Gene Ontology database (GO), and Pfam protein family database (Pfam) (Table 2). Among them, 42,149 (79.60\%) and 31,877 (60.20\%) unigenes have

Table 2 List of A. fibrillifera transcriptome annotations

\begin{tabular}{lll}
\hline Public database & No. of unigene hit & Percentage (\%) \\
\hline NR & 42,149 & 79.60 \\
NT & 25,038 & 47.28 \\
SwissProt & 27,893 & 52.67 \\
KOG & 29,090 & 54.93 \\
KEGG & 30,506 & 57.61 \\
GO & 11,956 & 22.58 \\
Pfam & 31,877 & 60.20 \\
\hline
\end{tabular}

NR Non-redundant protein sequence database, NT NCBI non-redundant nucleotide sequences, SwissProt Swiss-Prot protein sequence database, KOG Eukaryotic Orthologous Groups, KEGG Kyoto Encyclopedia of Genes and Genomes, GO Gene Ontology database, Pfam Pfam protein family database been annotated in the NR and Pfam databases, respectively. The unigenes annotated by the NR database were analyzed (Fig. 1). The E-value distribution revealed that $23.69 \%$ of the homologs varied from $1.0 \mathrm{E}^{-5}$ to $1.0 \mathrm{E}^{-30}$, while the E-value of most sequences (72.26\%) was less than $1.0 \mathrm{E}^{-30}$, which indicated strong homology (Fig. 1A). For the similarity distribution, $46.44 \%$ of the matches had 80 to $100 \%$ similarities as reported in the BlastX results, while $28.29 \%$ of the matches varied from 60 to $80 \%$ in similarity. Only $25.27 \%$ showed less than $60 \%$ similarities with the corresponding gene sequences (Fig. 1B). The score of $61.51 \%$ of the unigenes was $\geq 200$, among which $10.88 \%$ presented values $\geq 1000$ (Fig. 1C). Auricularia subglabra TFB-10046 SS5 exhibited the most BlastX matches (67.09\%), followed by Exidia glandulosa HHB 12029 (7.85\%) (Fig. 1D). In total, 37,530 coding sequences were detected using TransDcoder (Supplementary Table S1), and 4600 simple sequence repeat markers were distributed in 3627 unigenes.

\section{Identification of DEGs}

In total, 14,235 DEGs, 4996 up-regulated and 9239 down-regulated, were detected under drought-stress conditions (Fig. 2). During the rehydration process 8539 DEGs, 4373 up-regulated and 4166 down-regulated were found. There were 4703 common DEGs under droughtstress and rehydration conditions.

\section{DEG enrichment analyses of responses to drought stress and rehydration}

A total of $1461 / 5$ and $967 / 9$ GO terms were enriched/ significantly enriched under drought-stress and

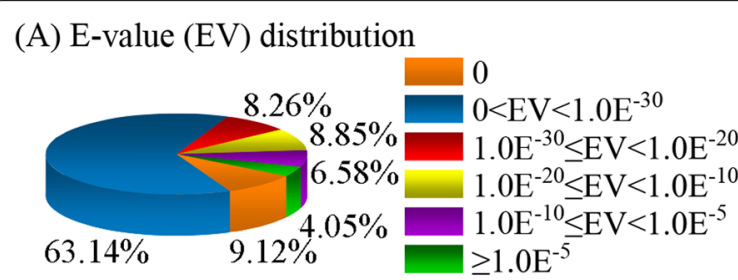

(C) Score (Sc) distribution
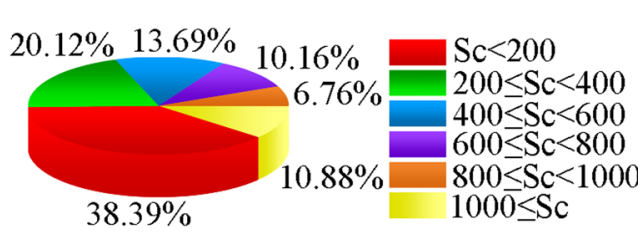

(B) Similarity (Si) distribution

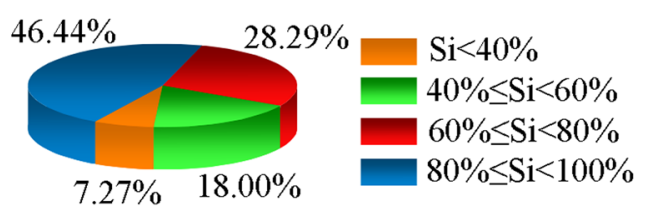

(D) Species distribution

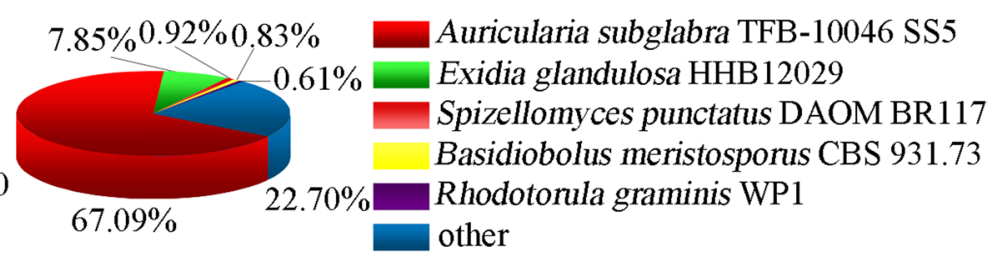

Fig. 1 Characteristics of homology search among unigene sequences aligned by BlastX to the Non-redundant protein sequence database. A E-value distribution of BlastX hits for each unigene with an E-value threshold of $1.0 \mathrm{E}^{-5}$. B Similarity distribution of the top BlastX hits for each unigene. $\mathbf{C}$ Score distribution of the top BlastX hits for each unigene. D Species distribution of the top BlastX hits for each unigene sequence with a cut-off E-value of $1.0 \mathrm{E}^{-5}$ 


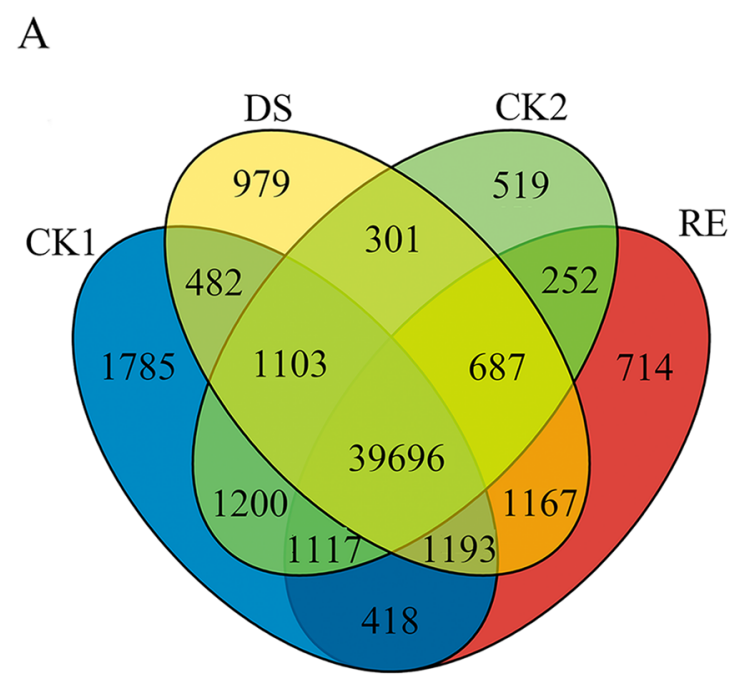

B

Fig. 2 Number of DEGs in A. fibrillifera under drought-stress and rehydration conditions. A Venn diagrams of DEGs under drought-stress and rehydration conditions. B Number of up- and down-regulated DEGs under drought-stress and rehydration conditions. DS, drought stress; RE, rehydration; CK1 and CK2 were the controls of DS and RE, respectively. FDR $\leq 0.05$ and $\left|\log _{2} F C\right| \geq 1$ were used as the thresholds to judge the significance of gene expression differences

rehydration conditions, respectively. The structural categories of 'ribosome' and 'ribosome and translation' were significantly enriched under both drought-stress and rehydration conditions (Table 3). The up-regulated DEGs under drought stress were significantly enriched in 'MAPK activity' $(0.26 \%)$, 'mitochondrion' $(0.82 \%)$, '1-alkyl-2-acylglycerosphosphorine esterase activity' $(0.10 \%)$, 'cytochrome-c oxidase activity' $(0.40 \%)$, 'lipid binding' ( $0.20 \%)$, and 'fungal-type cell wall organization' (0.18\%) (Supplementary Table S2). The down-regulated
DEGs were mainly enriched in 'structural condition of ribosome' (5.50\%), 'translation' (5.09\%), and 'ribosome' (4.07\%). Ribosome function was inhibited, and the translation process in cells was reduced. During the rehydration process, DEGs were significantly upregulated in 'response to stress' (0.59\%), 'MAPK activity' $(0.23 \%)$, and 'transmembrane transporter activity' (0.23\%). The enriched terms for down-regulated DEGs were similar to those under drought-stress conditions.

Table 3 Significantly enriched GO terms under drought-stress and rehydration conditions

\begin{tabular}{|c|c|c|c|}
\hline Stages & GO terms & Gene number & Q-value \\
\hline \multirow[t]{5}{*}{ Drought stress } & Structural constituent of ribosome & 726 & $6.88 \mathrm{E}^{-20}$ \\
\hline & Translation & 678 & $2.35 \mathrm{E}^{-16}$ \\
\hline & Ribosome & 533 & $3.78 \mathrm{E}^{-08}$ \\
\hline & Cytosolic large ribosomal subunit & 104 & 0.01 \\
\hline & Cytochrome-c oxidase activity & 33 & 0.02 \\
\hline \multirow[t]{9}{*}{ Rehydration } & Translation & 446 & $8.88 \mathrm{E}^{-20}$ \\
\hline & Structural constituent of ribosome & 469 & $1.44 \mathrm{E}^{-18}$ \\
\hline & Ribosome & 360 & $1.45 E^{-12}$ \\
\hline & Translation elongation factor activity & 55 & 0 \\
\hline & Transmembrane transporter activity & 14 & 0 \\
\hline & Fungal-type cell wall & 19 & 0 \\
\hline & Small ribosomal subunit & 56 & 0.01 \\
\hline & Actin cytoskeleton & 16 & 0.02 \\
\hline & Cell adhesion molecule binding & 12 & 0.05 \\
\hline
\end{tabular}


However, their percentages changed to $6.82,6.34$, and $5.23 \%$, respectively.

The significantly enriched KEGG pathways were determined to analyze the DEGs' biological functions. There were 124 KEGG pathways involved in drought stress, among which 'tyrosine metabolic', 'ribosome', 'phagosome', and 'aflatoxin biosynthesis' pathways were significantly (Q-value $\leq 0.05$ ) enriched (Table 4 ). Among these pathways, DEGs of 'ribosome', 'amino sugar and nucleoside sugar metabolism', and 'MAPK signaling-yeast' pathways accounted for $14.39,10.45$, and $10.11 \%$, respectively. More than half of the DEGs in the 'amino sugar and nucleoside sugar metabolic' pathway were annotated as chitinase. In addition, many pathways related to sugar and amino acid synthesis were enriched, and 1449 DEGs were annotated to these pathways.

During the rehydration process, the DEGs were enriched in 122 KEGG pathways, with the main pathways being 'diterpenoid biosynthesis', 'butanoate metabolism, ' $\mathrm{C}_{5}$-branched dibasic acid metabolism,' 'ribosome', 'aflatoxin biosynthesis', 'cyanoamino acid metabolism', and 'methane metabolism'. Compared with drought stress, 'diterpenoid biosynthesis', 'butanoate metabolism, and ' $\mathrm{C}_{5}$-branched dibasic acid metabolism' pathways were specifically enriched. The number of up-regulated DEGs during the rehydration process was similar to that under drought-stress conditions. However, the numbers of down-regulated DEGs and DEGs per pathway during the rehydration process were approximately $50 \%$ the numbers found under drought-stress conditions. Many DEGs involved in the rehydration process were different from those activated under drought-stress conditions, indicating that the DEGs were pathway- and mechanism-specific.

Some enriched pathways, such as proline, were consistent with our physiological data, although they were not significantly enriched. Therefore, 'tyrosine metabolism', 'caffeine metabolism', 'ribosome', 'phagosome', 'amino sugar and nucleoside sugar metabolism', and 'proline and arginine metabolism', as well as 'MAPK signaling pathway-yeast' pathways might play significant roles in the drought tolerance of $A$. fibrillifera. 'Dieterpenoid biosynthesis', 'butanoate metabolism', and ' $\mathrm{C}_{5}$-branched dibasic acid metabolism' were significantly enriched during the rehydration process, which might be of paramount importance in the rehydration responses of $A$. fibrillifera.

\section{Expression levels of genes involved in responses to drought stress Antioxidative substance-related genes}

Melanin has antioxidant and free radical scavenging activities [42]. In this study, 88 DEGs were involved in the 'tyrosine metabolic' pathway. The greatest number of DEGs was annotated as tyrosinase (EC: 1.14 .18 .1 ) in this pathway, which plays a master role in catalyzing melanin synthesis. The level of tyrosinase expressed during

Table 4 Top 10 pathways enriched with differentially expressed genes under drought-stress and rehydration conditions

\begin{tabular}{|c|c|c|c|}
\hline Stages & Pathways & Gene number & $Q$ value \\
\hline \multirow[t]{10}{*}{ Drought stress } & Ribosome & 1295 & $2.13 \mathrm{E}^{-53}$ \\
\hline & Phagosome & 167 & $2.24 \mathrm{E}^{-05}$ \\
\hline & Aflatoxin biosynthesis & 101 & 0.01 \\
\hline & Tyrosine metabolism & 88 & 0.03 \\
\hline & Diterpenoid biosynthesis & 32 & 0.08 \\
\hline & Caffeine metabolism & 5 & 0.41 \\
\hline & Phenylalanine metabolism & 58 & 0.41 \\
\hline & Phosphonate and phosphinate metabolism & 8 & 0.41 \\
\hline & Butanoate metabolism & 29 & 0.41 \\
\hline & Beta-alanine metabolism & 68 & 0.44 \\
\hline \multirow[t]{10}{*}{ Rehydration } & Ribosome & 770 & $2.30 \mathrm{E}^{-27}$ \\
\hline & Diterpenoid biosynthesis & 27 & 0 \\
\hline & Aflatoxin biosynthesis & 67 & 0 \\
\hline & Butanoate metabolism & 25 & 0 \\
\hline & $\mathrm{C}_{5}$-Branched dibasic acid metabolism & 6 & 0.01 \\
\hline & Cyanoamino acid metabolism & 44 & 0.01 \\
\hline & Methane metabolism & 56 & 0.04 \\
\hline & Fructose and mannose metabolism & 34 & 0.12 \\
\hline & Tyrosine metabolism & 53 & 0.12 \\
\hline & Thiamine metabolism & 31 & 0.12 \\
\hline
\end{tabular}


the rehydration process was lower than under droughtstress conditions. The $\log _{2} \mathrm{FC}$ value of tyrosinase CL504. Contig14_All was the highest (4.71) under drought-stress conditions, but not after rehydration. Unigene10928_All (homogenesate1,2-dioxygenase (EC: 1.13.11.5) was highly down-regulated under drought-stress conditions, and this contributed to melanin synthesis. These genes may play vital roles in melanin accumulation, which alleviates the oxidative damage produced under drought stress conditions.

There were five DEGs in the 'caffeine metabolic' pathway that were annotated as members of the CL2727 cluster. However, these five genes were all annotated to urate oxidase (EC: 1.7.3.3). The decrease in urate oxidase activity reduced the conversion of caffeine to 3,6,8-trimethylantoin, which improved caffeine accumulation under drought-stress conditions. On the contrary, most of these genes were up-regulated during the rehydration process.

The 'peroxisome' pathway is important in resisting oxidative stress, and superoxide dismutase (SOD) and catalase (CAT) are produced in this pathway. In total, 69 DEGs were annotated in the 'peroxisome' pathway under drought-stress conditions. Unigene14272_All (peroxin-13) was highly up-regulated under drought-stress conditions, but not after rehydration. Thus, antioxidants enhance the drought tolerance of $A$. fibrillifera.

\section{Osmotic adjustment-related genes}

Soluble sugars and amino acids have crucial roles in osmotic adjustment. A total of 1449 DEGs were annotated in pathways related to osmotic adjustment, such as 'amino sugar and nucleotide sugar metabolism, 'fructose and mannose metabolism,' 'mannose type O-glycan biosynthesis', and 'proline and arginine metabolism' (Supplementary Table S3). There were 43 DEGs in the mannose pathway. Mannose performs an important role in osmotic adjustment [43]. 'Mannose type O-glycan biosynthesis' was significantly enriched, and the $\log _{2} \mathrm{FC}$ value of CL8620.Contig2_All reached 7.43 under drought-stress conditions. Additionally, four DEGs of the CL2554 gene (dolichyl-phosphate-mannose-protein mannosyltransferase) cluster were annotated, and their $\log _{2}$ FC values were $>5$ under drought-stress conditions, but their expression was not observed after rehydration.

Proline plays a vital role in drought tolerance. In this study, 55 DEGs were annotated in the 'proline and arginine metabolic' pathway. Unigene15963_All in the 'alanine, aspartate and glutamate metabolic' pathway and CL1716.Contig2_All in the 'arginine, proline and tryptophan metabolic' pathway were highly expressed under drought-stress conditions, but not after rehydration. In particular, CL1716.Contig2_All played important roles in multiple amino acid and sugar metabolic pathways. On the contrary, CL2495.Contig1_All was down-regulated under drought-stress conditions, having a $\log _{2} \mathrm{FC}$ value of -7.50 . Thus, it should play negative roles in multiple amino acid metabolic pathways.

\section{Genes in the 'ribosome' pathway}

Ribosomes are responsible for translation. The GO and KEGG annotations determined that a large number of DEGs was annotated in the 'ribosome' pathway. Overall, 1295 DEGs were detected under drought stress conditions, among which 1046 presented $\left|\log _{2} \mathrm{FC}\right|$ values $\geq 2$. Additionally, 770 DEGs during the rehydration process were enriched in the 'ribosome' pathway. Thus, more 'ribosome' pathway DEGs participated in the response to drought stress than to rehydration.

\section{Genes in the 'phagosome' pathway}

Foreign substances and damaged cells may be swallowed into phagosomes through actin endocytosis. Here, 23 actin beta/gamma 1 genes were involved in the 'phagosome' pathway, with the expression level of CL118. Contig41_All being the highest. In addition to regulating the intracellular ionic or $\mathrm{pH}$ balance, some ATPases drive numerous physiological or biological processes by 'energy coupling', including receptor-mediated endocytosis, intracellular membrane trafficking, protein degradation, and coupled transport [44]. Here, 12 vacuolar-type $\mathrm{H}^{+}$-ATPase (V-ATPase) genes, including CL4156.Contig1_All, CL4156.Contig2_All and CL4156.Contig3_All, were annotated in this pathway. These V-ATPases exist on phagocytic membranes and may help break down harmful substances.

\section{Genes of the signaling pathways}

The MAPK signal transmission network is important and has key roles in gene expression regulation and cytoplasmic functional activities. In total, 910 DEGs were annotated in the 'MAPK signaling pathway-yeast', and 282 were up-regulated under drought-stress conditions. There were 487 DEGs annotated as flocculation protein FLO11, 95 DEGs as mucin-19, and 408 DEGs as chitinase. Flocculation protein FLO11-related genes Unigene104_All, CL6788.Contig3_All, CL3858.Contig3_All, and CL1874.Contig4_All were highly expressed under drought-stress conditions, after which their levels decreased rapidly following rehydration. The differences in their $\log _{2} \mathrm{FC}$ values between drought-stress and rehydration conditions were $>9$.

\section{Chitinase-related genes}

Hydrolases are involved in maintaining the plasticity of cell walls and may play roles in the branching and crosslinking of polymers [45]. A large number of the 
DEGs (907) were annotated as chitinases in the 'amino sugar and nucleoside sugar metabolic' pathway, with 306 up-regulated and 601 down-regulated DEGs being identified under drought-stress conditions. The $\log _{2} \mathrm{FC}$ values of 155 DEGs were > 2 under drought-stress conditions, and Unigene104_All, Unigene5550_All, CL8307.Contig2_ All and Unigene13034_All were very sensitive to drought stress. They were abundantly expressed under droughtstress conditions, but not, or very lowly, expressed after rehydration.

\section{Expression of genes involved in responses to rehydration Genes related to gibberellin (GA) synthesis}

The 'dieterpenoid biosynthesis', 'butanoate metabolism, and ' $\mathrm{C}_{5}$-branched dibasic acid metabolic' pathways have important roles during the rehydration process. In total, 32 DEGs were annotated under the 'diterpenoid biosynthetic' pathway, and 27 were annotated during the rehydration process. Ent-kaurene oxidase catalyzes gibberellic aldehyde synthesis, which is a GA precursor. Ent-kaurene oxidase genes CL264.Contig8_All and Unigene8480_All were up-regulated during the rehydration process, indicating that GA plays major roles in breaking dormancy and improving growth after rehydration in A. fibrillifera (Supplementary Table S4).

\section{The genes related to 4-aminobutyric acid (GABA) synthesis}

GABA may act respond to osmotic pressure and alleviate water stress [46]. 'Butanoate metabolism' was significantly enriched during the rehydration process, and GABA was the main product of this pathway. There were 69 DEGs in the 'butanoate metabolic' pathway, among which 29 were annotated during the rehydration process. After rehydration, the $\log _{2} \mathrm{FC}$ value of Unigene3125_All (glutamate decarboxylase) reached 3.30, which was 4.74 fold greater than under drought-stress conditions. This gene plays an important role in the transformation of L-glutamate into GABA. It was up-regulated during the rehydration process, and this increased GABA synthesis.

\section{The genes in ' $C_{5}$-branched dibasic acid metabolism'}

Valine, leucine, and isoleucine are growth-promoting amino acids that act as carbon sources during starvation, and they can be integrated into the tricarboxylic acid (TCA) cycle to produce respiratory energy [47]. These amino acids are produced by ' $\mathrm{C}_{5}$-branched dibasic acid metabolism'. In this study, six up-regulated DEGs were enriched in ' $\mathrm{C}_{5}$-branched dibasic acid metabolism' during the rehydration process. Among them, CL4410. Contig1_All, CL4410.Contig2_All, CL6195.Contig1_All, and CL8753.Contig2_All were annotated as acetolactate synthase I/II/III large subunit, and the others (CL7598.
Contig2_All and CL7598.Contig3_All) as 3-isopropylmethylate dehydrogenase.

\section{Verification of DEGs by qPCR, protein expression levels, and physiological-biochemical data}

In total, 11 DEGs closely related to drought stress were selected for the qPCR analysis. All the genes amplification levels, as assessed by qPCR, agreed well with the RNA-seq patterns, and the correlation between RNA-seq and qPCR was measured using scatter plot changes, which displayed a positive correlation coefficient $\left(\mathrm{r}=0.9285, p=1.8715 \mathrm{E}^{-6}\right.$; Table 5; Supplementary Fig. S2).

A. fibrillifera-specific pathways, such as 'tyrosine metabolism', 'caffeine metabolism', 'butanoate metabolism,' 'biosynthesis of antibiotics', and 'phagosome', were also enriched by the proteome analysis (Table 6). Many DEG-corresponding differentially expressed proteins (DEPs) were detected in these pathways, and the expression levels displayed by some DEGs were consistent with those of the DEPs. These data demonstrated that the transcriptomes accurately reflected the responses of $A$. fibrillifera to drought stress and rehydration.

The melanin content of fruiting bodies under drought stress conditions was 10.19-fold higher than that of the control (Fig. 3A). After rehydration, the melanin content decreased slightly. The difference in melanin content was not significant between drought stress and rehydration conditions, which may be attributed to the short rehydration time (only $1 \mathrm{~h}$ ). D-mannose content and chitinase activities were significantly higher under drought stress than in the control. After rehydration, they started to decrease (Fig. 3B, C).

Table 5 Verification of RNA-seq results by qPCR

\begin{tabular}{lll}
\hline Gene ID & qPCR & RNA-seq \\
\hline CL8627.Contig6_All & -0.14 & -0.82 \\
CL1983.Contig1_All & 0.44 & -0.05 \\
CL456.Contig3_All & 0.40 & 0.41 \\
CL652.Contig1_All & 0.65 & 0.49 \\
CL6704.Contig1_All & 1.78 & 0.91 \\
CL4410.Contig1_All & 1.37 & 0.97 \\
CL2996.Contig9_All & 1.09 & 1.29 \\
CL118.Contig41_All & 1.06 & 1.67 \\
CL3812.Contig6_All & 1.55 & 2.52 \\
CL3209.Contig8_All & 2.83 & 4.37 \\
CL3274.Contig2_All & 3.05 & 4.97 \\
Unigene5564_All & 5.30 & 1.68 \\
R coefficient & 0.9285 & \\
p & $1.8715 E^{-6}$ & \\
\hline
\end{tabular}


Table 6 The expression levels of some specific DEGs/DEPs under drought-stress conditions in A. fibrillifera

\begin{tabular}{lllll}
\hline Gene ID & Pathways & Function & log $_{2}$ FC \\
\cline { 3 - 4 } & & & Gene & Protein \\
\hline Unigene219_All & Tyrosine metabolism & Tyrosinase & 3.41 \\
CL2727.Contig3_All & Caffeine metabolism & Urate oxidase & -1.25 & 2.36 \\
Unigene10455_All & Butanoate metabolism & Glutamate decarboxylase & -1.97 & 1.04 \\
CL4410.Contig1_All & & Acetolactate synthase activity & 1.01 \\
CL1463.Contig1_All & Biosynthesis of antibiotics & 3-oxoacyl-_acyl-carrier protein] reductase & 3.11 & 2.19 \\
Unigene5022_All & & Catalase & 2.89 & 3.98 \\
Unigene431_All & & Sterol 22-desaturase & -1.53 & 2.08 \\
CL5899.Contig1_All & Phagosome & Ras-related protein Rab-5C & -1.32 \\
\hline
\end{tabular}
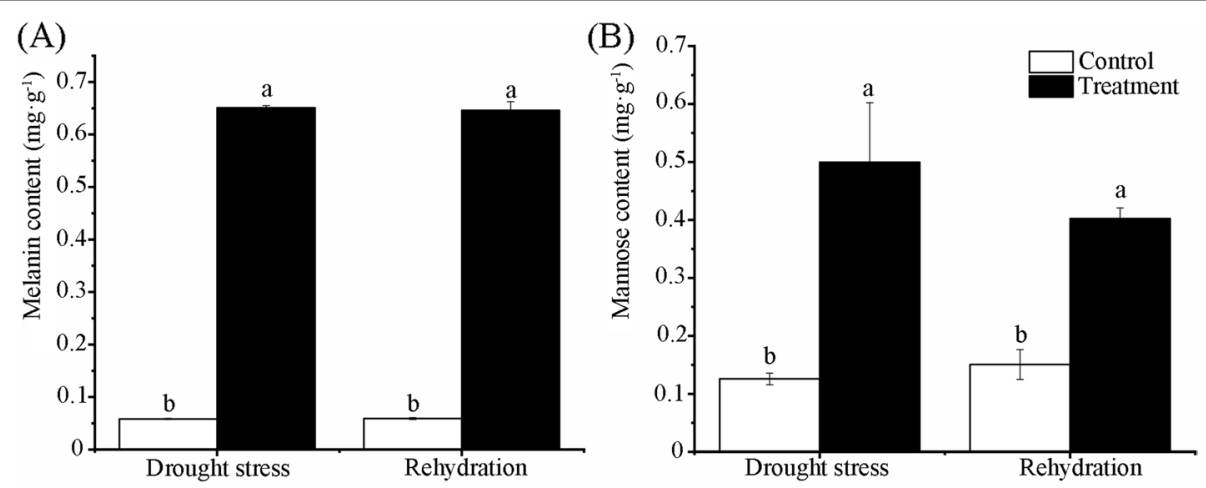

(C)

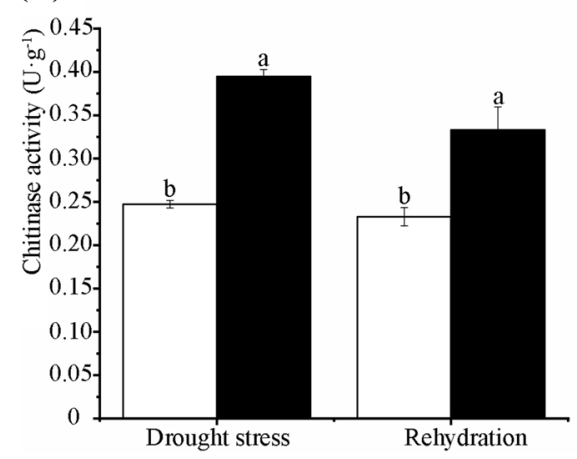

(D)

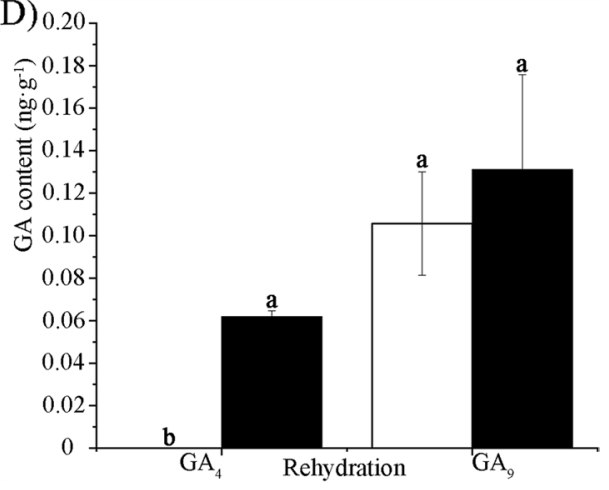

Fig. 3 Effects of drought stress on the contents of melanin $(\mathbf{A})$ and D-mannose $(\mathbf{B})$, chitinase activity $(\mathbf{C})$, and rehydration on the GA content (D) in A. fibrillifera. Bars show means \pm SDs $(n=3)$. Values with different letters are significantly different at $p<0.05$

Nine kinds of GAs were detected during the rehydration process in A. fibrillifera. The contents of $\mathrm{GA}_{4}$ and $\mathrm{GA}_{9}$ were higher than those of the control, respectively (Fig. 3D). GA 4 content showed significantly higher after rehydration than in the control. These physiological-biochemical results were consistent with the above transcriptome data.

\section{Discussion}

De novo sequencing and DEG analysis

Drought stress triggers a wide variety of fungal responses, ranging from molecular processes to physiological metabolism. In this study, 14,235 and 8539 DEGs were detected under drought-stress and rehydration conditions, respectively. In Auricularia heimuer, 
7056 predicted proteins that accounted for $43.43 \%$ of the entire genome were mainly distributed in five functional entries, 'binding,' 'catalytic activity', 'cellular process', 'metabolic process', and 'single-organism process' [48]. Similar results were obtained in this study. Most DEGs of $A$. fibrillifera were annotated as 'binding,' 'catalytic activity', 'cellular process,' 'membrane part', and 'organelle part.'

\section{Transcriptome responses to drought stress Antioxidative protection}

The exposure of plants to certain environmental stresses quite often leads to ROS generation, which causes oxidative damage and impairs normal cellular functions [49]. The ROS increase at the early stage of drought stress induces the enzymatic and non-enzymatic scavenging systems to sequester ROS, so that the radical scavenging ability and strong drought tolerance was maintained in Erythrodontium julaceum mosses [50]. Melanins can protect fungi from abiotic stresses. They are endowed with a remarkable antioxidative activity and well-recognized photoprotective properties [51]. Melanin has antioxidant and free radical scavenging activities. The melanin produced by Aureobasidium melanogenum XJ5-1 obtained from the Taklimakan Desert can play an important role in the adaptation of yeast strains to drought stress treatments [52]. A. pullulans and A. melanogenum are black-yeast-like surface colonizers and are commonly encountered as contaminants in hospitals. These species are able to produce melanin, which plays a role in protection against environmental stress and irradiation [53]. Certain fungi can produce melanin via dihydroxyphenylalanine, which is used by tyrosinases or laccases to hydroxylate tyrosine to dopaquinone, which then auto-oxidizes and polymerizes, producing black polyphenolic heteropolymers [42]. Gray-green dihydroxynaphtalene-melanins establish the structural integrity of conidial cell walls and their adhesive properties in Aspergillus fumigatus [54]. Dopaquinone (orthoquinone of 3,4-dihydroxyphenylalanine) is the precursor of melanin, and it is formed through the oxidation of L-tyrosine by the melanogenic tyrosinase [55]. In this work, most DEGs were involved in melanin synthesis in the 'tyrosine' pathway, and 24 DEGs were annotated as tyrosinase. These genes act as goalkeepers in every pathway of melanin synthesis. The expression levels of these DEGs under drought-stress conditions were significantly greater than those after rehydration. The highest $\log _{2} \mathrm{FC}$ value of these DEGs reached 4.71 under drought-stress conditions. Homogentic acid 1,2-dioxygenase negatively regulates the synthesis of melanin [56]. Here, a highly down-regulated homogentic acid 1,2-dioxygenase gene (Unigene10928_All) was also found. The melanin content of fruiting bodies under drought stress conditions was 10.19-fold higher than that of the control (Fig. 3A). These various DEGs work together to promote melanin accumulation.

Caffeine, a xanthine alkaloid, is an active ingredient in coffee and present in many foods and beverages. Caffeine is an effective antioxidant that can eliminate $\cdot \mathrm{OH}$, and its antioxidant ability is similar to that of glutathione, and significantly higher than that of ascorbic acid [57, 58]. In this experiment, five DEGs (enrichment ratio $=0.71$ ) were expressed in the 'caffeine metabolic' pathway under drought-stress conditions. They were all annotated as urate oxidase. However, they were not detected after rehydration. Thus, caffeine might perform crucial roles in A. fibrillifera's adaptation to drought stress.

The 'peroxisome', 'ascorbate', and 'aldarate metabolic' pathways were identified in this work. A total of 79 DEGs were annotated in the 'peroxisome' pathway, of which 69 were annotated under drought-stress conditions. CAT and SOD participate in hydrogen peroxide metabolism in the peroxisomal targeting sequence 1 system. Unigene14272_All (peroxin-13) was up-regulated under drought-stress conditions, but not after rehydration. The levels of glutathione reductase, glutathione peroxidase, and glutathione S-transferase increase during slow drying or during rehydration following rapid drying in the drought-tolerant moss Tortula ruralis [59]. NADPH plays important roles in maintaining the reduced glutathione content in cells [60]. In total, 39 DEGs in the 'glutathione metabolic' pathway were annotated under drought-stress conditions. CL8514.Contig2_All (glutathione peroxidase) was up-regulated under drought-stress conditions, but not after rehydration. Thus, these antioxidant enzymes may scavenge harmful ROS and free radicals to protect cell membranes and proteins under drought stress conditions in A. fibrillifera.

Sixty-three up-regulated DEGs were annotated in the 'aflatoxin biosynthesis' pathway under drought conditions. However, the expression levels of most DEGs $(74.60 \%)$ decreased rapidly at $1 \mathrm{~h}$ after rehydration. Aflatoxin may participate in A. fibrillifera's responses to drought stress by reducing oxidative damage [61].

\section{Osmotic adjustment}

In response to abiotic stresses, amino acid metabolism plays an important regulatory role because amino acids act as potential regulatory and signaling molecules, as well as precursors for energy-associated metabolites and numerous secondary metabolites [49]. In this study, CL1716.Contig2_All (amidase) enhanced GABA synthesis, and it was highly expressed $\left(\log _{2} \mathrm{FC}=7.72\right)$ under drought-stress conditions, but not after rehydration. It also participated in other amino acid metabolic pathways, such as 'tryptophan and phenylalanine metabolisms'. 
CL2495.Contig1_All, an aldehyde dehydrogenase $\left(\mathrm{NAD}^{+}\right)$ gene, was annotated in multiple amino acid metabolic pathways, including 'alanine, aspartate and glutamate metabolism', as well as in 'butanoate metabolism. Proline is the amino acid most associated with stress-related responses in plants. Its accumulation varies among species, but it can be 100-times greater under stress conditions compared with control conditions [62]. Proline synthesis appears to be the preferred method for withstanding prolonged osmotic stress in Jeotgalibacillus malaysiensis [63]. In this study, the 'proline and arginine metabolic' pathway was enriched under drought-stress conditions. There were 16 up- and 38 down-regulated DEGs under drought-stress conditions. Proline iminopeptidase is a constitutive enzyme that digests a large number of n-proline copolymers to form proline [64]. In total, seven DEGs were annotated as proline iminopeptidase, and their expression levels were significantly greater under drought-stress conditions than after rehydration. These DEGs promoted proline accumulation under drought-stress conditions. This was consistent with the increased proline content under drought-stress conditions in the physiological experiment (unpublished data).

A water deficit during drought stress inevitably leads to osmotic stress. Under osmotic-stress conditions, the accumulations of sugars and amino acids, as well as $\mathrm{K}^{+}$ and glycine betaine, help organisms to resist osmotic stress [65]. Staphylococcus xylosus responds to salt stress by overexpressing genes related to the synthesis of osmotic protectants [66]. Here, 10 pathways related to osmotic adjustment, such as 'fructose and mannose metabolism', and 'amino acid metabolic pathways', were identified. CL8620.Contig2_All in 'mannose type O-glycan biosynthesis' was highly expressed under droughtstress conditions. D-mannose content was significantly higher under drought stress than in the control. After rehydration, it started to decrease (Fig. 3B).

\section{Ribosome}

Ribosomes are the centers of translation, which is the first step in the synthesis of many regulatory substances. Importantly, the regulation of the elongation phase of translation is broadly utilized in response to cellular stress, and is impacted by various mechanisms, including post-translational modifications of elongation factors [67] and ribosomes [68-70]. Most of the DEGs were enriched in the 'ribosome' pathway. In total, 1295 DEGs were detected under drought stress conditions, among which 1046 presented $\left|\log _{2} \mathrm{FC}\right|$ values $\geq 2$. Additionally, 770 DEGs during the rehydration process were enriched in the 'ribosome' pathway. Thus, more 'ribosome' pathway DEGs participated in the response to drought stress than to rehydration.

\section{Phagosome}

Phagosomes are key organelles responsible for the innate ability of macrophages to participate in clearing apoptotic cells and maintain overall homeostasis [71]. 'Phagosome' pathway is significantly affected by drought in wheat [72]. This pathway requires the activity of a V-ATPase, and is induced by osmotic imbalances within endolysosomal compartments [73]. In this work, the 'phagosome' pathway was significantly enriched under drought-stress conditions. There were 23 DEGs in this pathway, among which CL118.Contig41_All had the highest expression level. The CL118 gene cluster was annotated as actin beta/gamma 1, which is involved in F-actin-controlled phagocytosis.

\section{Signal transduction}

In all the fungal species, the 'MAPK' pathway plays important role in their physiology and development, including responses to different stresses, resistance to temperature changes, cell wall assembly and integrity, cell-cell signaling, and responses to damage-associated molecular patterns [74]. The central signal transduction pathway of $A$. fumigatus during hyperosmotic stress is the high osmolarity glycerol MAPK cascade [75]. Some MAPK cascade genes are differentially expressed in cotton under abiotic stress conditions, after plant hormone treatments and especially under drought-stress conditions [39]. Drought stress induces MAPK cascade responses in cotton, and when the cotton MAPK kinase gene ghmkk3 is overexpressed in tobacco, drought tolerance is enhanced [76]. In this experiment, 282 up-regulated and 627 down-regulated DEGs in 'MAPK signaling pathway-yeast' were identified under drought-stress conditions. Unigene104_All (chitinase), CL1874.Contig4_All (signaling mucin HKR1), Unigene13034_All (chitinase), and Unigene14521_All (flocculation protein FLO11) were highly expressed under drought-stress conditions, but not, or lowly, expressed after rehydration.

Many stresses trigger transient increases in minor phospholipids, such as phosphoinositides and phosphatidic acid [77]. In this study, 37 DEGs were annotated in the 'phosphatidylinositol signaling' pathway. Among them, the three calmodulin genes, Unigene2205_All, Unigene7676_All and Unigene5387_All, had very obvious responses to drought stress and rewatering. They were significantly up-regulated under drought-stress conditions, but significantly down-regulated after rehydration. Their largest $\log _{2} \mathrm{FC}$ difference reached 12.89. In addition, the Unigene9338_All (1-phosphatidylinositol4-phosphate 5-kinase) showed the highest expression in this pathway, which is involved in the synthesis of phosphatidylinositol 4-phosphate to phosphatidylinositol 
4,5-bisphosphate. As a result, MAPK and phosphatidylinositol signaling system pathways may participate in A. fibrillifera's responses to drought stress and rewatering, and then lead to drought-tolerant effects on physiology and growth.

\section{Chitinase}

Fungal chitinases play an important role not only in degradation, but also in morphogenesis, cell division, autolysis, and acquisition of chitin [45]. PcchiB1 in Penicillium chrysogenum, which potentially encodes a class $\mathrm{V}$ chitinase, is responsible for cell wall integrity. The knockout strains showed distinct mycelial growth, but control strains presented highly fragmented and dispersed hyphae with the formation of only a few smallfringed pellets. In addition, the increase of PcchiB1 transcript levels led to the degradation of chitin in the fungal cell wall, which provided new nutritional resources for fungi [78]. The extending native stipe walls of Coprinopsis cinerea were associated with the release of $\mathrm{N}$-acetylglucosamine and chitinases, especially ChiE1 and CHIII. These two chitinases reconstituted the wall extension of the heat-inactivated stipe, and their double knockdown reduced stipe elongation, mycelium growth, and wall extension [79]. The overexpression of chitinases in transgenic plants provides resistance to abiotic and biotic stresses [80]. In this work, it was shown that the fruiting body shrank and became hard under drought stress conditions (Supplementary Fig. S3); once watered, it would absorb water quickly and become soft and stretched. All chitinase genes were annotated as the chitinases [EC:3.2.1.14] by KEGG analysis. 306 upregulated and 601 down-regulated DEGs were identified under drought-stress conditions, and the $\log _{2} \mathrm{FC}$ values of many chitinase related DEGs were very high, with the value of Unigene104_All being the greatest (10.15). Chitinase activities were significantly higher under drought stress than in the control (Fig. 3C). A total of 73 DEGs were grouped into seven GO terms related to cell wall, among which 19 were annotated as belonging to the chitinase [EC: 3.2.1.14] type and 50 as various proteins. Therefore, many DEGs related to chitinase may activate cell wall metabolic pathways and remodeling in order to adapt to drought stress in A. fibrillifera. We will focus on their classification, functions, and mechanisms in future research.

The main function of abscisic acid (ABA) is to regulate the plant's water balance and osmotic stress tolerance [81]. However, in this research, the pathways and genes associated with $\mathrm{ABA}$ synthesis or metabolism were not found. ABA occurs mainly in vascular plants, such as angiosperms, gymnosperms, and ferns. Therefore, unlike in plants, ABA did not play key roles in A. fibrillifera's responses to drought stress.

\section{Transcriptome responses to rehydration GA synthesis}

GA is a diterpenoid and an important phytohormone that promotes organ expansion and developmental changes. To date, the GA synthetic pathway in fungi is a mevalonate pathway. In this study, 'dieterpenoid biosynthesis' pathway was significantly enriched during the rehydration process, in which all the DEGs were annotated to GA synthesis. CL264.Contig8_All is an ent-kaurene oxidase that was up-regulated after rehydration, but downregulated under drought-stress conditions. In contrast, CL5200.Contig3_All is a GA 2 beta dioxygenase that was down-regulated after rehydration, but up-regulated under drought-stress conditions. The two genes produce GA during the rehydration process, but degrade GA under drought-stress conditions. $\mathrm{GA}_{4}$ content showed significantly higher after rehydration than in the control. Thus, $\mathrm{GA}_{4}$ may break dormancy and promote cell division and growth during the rehydration process in $A$. fibrillifera.

\section{GABA synthesis}

GABA is a non-protein amino acid that is widely distributed throughout the biological world and is a suitable nitrogen source for many fungi [82]. In plants, GABA has multiple functions under non-stressed and stressed conditions. Exogenous applications of GABA confer greater stress tolerance by modulating the expression of genes involved in plant signaling, transcriptional regulation, hormone biosynthesis, ROS production, and polyamine metabolism [83]. Exogenous GABA effectively alleviates growth inhibition caused by adverse environmental conditions (e.g., drought, salt, extreme temperature, water, light, or oxygen stress) [84, 85]. Exogenous GABA improves sporulation in Stagonospora nodorum and Botryosphaeria sp. (class Dothideomycetes) [86]. Here, 'butanoate metabolism' was significantly enriched during the rehydration process, and its main product is GABA. Unigene16234_All and Unigene3125_All were annotated as glutamate decarboxylase (EC: 4.1.1.15) that convert L-glutamate into GABA, which had a very high $\log _{2} \mathrm{FC}$ value. Therefore, GABA may contribute to the sporulation and rapid growth recovery of A. fibrillifera after rehydration.

\section{$C_{5}$-dicarboxylic acid metabolism}

In the ' $\mathrm{C}_{5}$-dicarboxylic acid metabolism' pathway, the synthesis of valine, leucine, and isoleucine is activated. Valine, leucine, and isoleucine are branched chain amino acids that are used as carbon sources to promote growth. 
The carbon skeletons of branched chain amino acids are generally converted to precursors or intermediates of the TCA cycle. The oxidation of leucine, isoleucine, valine, and lysine directly feeds electrons into the mitochondrial electron transport chain $[47,87,88]$. Because the ATP production of leucine, isoleucine, and valine is particularly high, the amounts of ATP produced by phosphorylation at the substrate level in the TCA cycle are increased [89]. In this study, six up-regulated DEGs were annotated in the ' $\mathrm{C}_{5}$-dicarboxylic acid metabolism' pathway during the rehydration process. They might provide energy and carbon skeletons for growth recovery after rehydration.

\section{Health care components in A. fibrillifera fruit bodies}

In this study, we found many genes related to antibiotics, vitamins, and other health-related ingredients in $A$. fibrillifera. Diterpenoids are found mainly in fungi and plants, and they possess a wide spectrum of important biological activities, such as anti-inflammatory, anti-cancer, and anti-parasitic [90]. In total, 105 DEGs related to diterpenoids were identified in the transcriptome analysis. There were 3734 DEGs involved in the biosynthesis of antibiotics, such as 'penicillin and cephalosporin biosynthesis' (63 DEGs) and 'carbapenem biosynthesis' (16 DEGs). In total, 280 DEGs were annotated to 'thiamine metabolism, mainly in 'vitamin $\mathrm{B}_{6}$ metabolism' (68 DEGs). Thus, A. fibrillifera is rich in human health care-related substances, which are worthy of further exploration.

\section{Conclusion}

In total, 14,235 and 8539 DEGs were detected under drought-stress conditions and during the rehydration process, respectively. 'Tyrosine metabolism', 'caffeine metabolism', 'ribosome', 'phagosome', and 'proline and arginine metabolism, as well as 'peroxisome' and 'MAPK signaling pathway-yeast' pathways, were enriched under drought stress conditions. The strong drought tolerance of A. fibrillifera may be mainly attributed to ROS scavenging, osmoregulation, signal transduction, cell wall remodeling, and phagocytosis. $\mathrm{GA}_{4}$ and GABA might promote the rapid recovery of growth after rehydration. Some important candidate genes (such as Unigene219 All, CL2727.Contig3_All, Unigene10455_All, CL4410. Contig1_All, and CL1463.Contig1_All) related to drought stress and rehydration were also found. Elucidating the function of these drought/rehydration-related genes will be valuable for genetic modification in Auricularia. Finally, many genes related to antibiotics, vitamins, and other health-related ingredients were found in A. fibrillifera, which is a nutritious food for humans. The outcomes of proteomic and physiological-biochemical analyses were consistent with the transcriptome data. These results shed light on the mechanisms of drought tolerance and rehydration, and they provide a valuable reference for Auricularia breeding and its cultivation. Further, the RNA-Seq data in the public repository have a wide variety of applications and accelerate the exploration in Auricularia researches.

\section{Materials and methods}

\section{Material, growth conditions, and sampling}

The fruiting bodies of drought-tolerant Auricularia fibrillifera cultivar 'CSLZ' was used for this experiment. This strain was obtained from tissue isolation, it was maintained in a potato-dextrose agar (PDA) medium at $44^{\circ} \mathrm{C}$, and was inoculated into the culture medium to produce the fruiting bodies. Its culture medium consisted of $83 \%$ sawdust, $14 \%$ wheat bran, $1 \%$ bean bran, $1 \%$ gypsum, and $1 \%$ lime. In total, $1 \mathrm{~kg}$ of mixed substrate was placed in heat-resistant polyethylene bags and then autoclaved for $1.5 \mathrm{~h}$ at $121^{\circ} \mathrm{C}$. The sterilized medium was inoculated with $0.5 \%$ grain spawn and maintained at $25^{\circ} \mathrm{C}$ in the dark. When the culture medium was fully colonized by mycelia, the polyethylene bags were removed, and the substrate was placed in a culture room $\left(25 \pm 1{ }^{\circ} \mathrm{C}, 15\right.$-h naturally scattered light/9-h dark). The bags were sprayed regularly with water, approximately eight times per day, with $15 \mathrm{~mL}$ of water per bag of substrate. When the diameters of the fruit bodies reached 2 to $3 \mathrm{~cm}$, droughtstress treatments were started, and the fruit bodies on the substrate dehydrated naturally. Regularly watered fruit bodies on the substrate were used as controls. When the water loss rate of fruit bodies reached $60 \%$ (DS) compared with its respective control (CK1), uniformly sized fruit bodies were collected as the first samples. After, the fruit bodies on the substrate were rewatered regularly. The second sampling was performed when the water loss rate of fruit bodies was 50\% (RE, $1 \mathrm{~h}$ after rehydration) compared with its respective control (CK2). These sampling stages were chosen on the basis of phenotypic and physiological data. Each sample pool included 15 individual fruit bodies, and three biological replications were employed in this experiment. All the samples were immediately frozen in liquid nitrogen after sampling and stored at $-80^{\circ} \mathrm{C}$ for further use.

\section{Total RNA extraction, CDNA library construction, and sequencing}

Total RNA was extracted using a TRIzol ${ }^{\circledR}$ reagent kit (Tiangen Biotech, Beijing, China) in accordance with the manufacturer's instructions, and then treated with TaKaRa RNase-free DNase I for $30 \mathrm{~min}$. The quality and quantity of total RNA were estimated using a NanoDrop TM (Thermo Fisher Scientific, Waltham, MA, USA). cDNA library construction was accomplished 
using cDNA library construction Kit (Beijing Genomics Institute, Shenzhen, China), and then, the libraries were subjected to paired-end read sequencing on the BGISEQ-500 platform at the Beijing Genomics Institute. Briefly, $20 \mu \mathrm{g}$ of total RNA per sample was mRNA enriched [enrichment of mRNA containing Poly(A) tails by magnetic beads with oligo dT] or underwent rRNA removal (hybridization of rRNA with a DNA probe). After that, the mRNA was randomly fragmented in fragmentation buffer, transcribed with random N6 primers, and double-stranded cDNA was then synthesized. The end of the synthesized doublestranded DNA was flattened and phosphorylated at the $5^{\prime}$ end. The $3^{\prime}$ end was sticky and protruded from an "A", which was connected with a joint protruding from a " $T$ ". The linkage products were amplified by PCR using specific primers. The PCR product was heat denatured into a single strand, and then, the single-strand DNA library was obtained by circularizing the single-strand DNA with a bridge primer. Then, high-throughput sequencing was performed on the BGISEQ-500 platform at the Beijing Genomics Institute.

\section{RNA-sequencing (RNA-seq) data processing and de novo assembly}

The raw paired-end reads were cleaned by removing adapter sequences, empty reads, and low-quality reads (reads with $>5 \%$ unknown base pairs ' $\mathrm{N}$ ') using SOAPnuke (Beijing Genomics Institute, version: 1.4.0, parameter: $-15,-\mathrm{q} 0.5,-\mathrm{n} 0.1)$ and trimmomatic software (version: 0.36, parameter: Illuminaclip:2:30:10, Leading:3, Trailing:3, Slidingwindow:4:15, Minlen:50) [91, 92]. Because there was no reference genome, Trinity de novo transcriptome assembly software was used for the transcriptome assembly of RNA-seq data from A. fibrillifera [93].

\section{Sequence annotation and classification}

Using Blast $\mathrm{X}$, the sequences were searched against the NCBI non-redundant (NR) protein database with a cutoff E-value of $10^{-5}$ for annotation [94]. Gene Ontology (GO) terms were extracted from the annotation of high scoring BLAST matches in the NCBI NR protein database (E-value $\leq 1.0 \times 10^{-5}$, http://www.ncbi.nlm.nih.gov) using Blast2go (version: 2.5.0, parameter: default) [95], after which the GO categories were sorted using in-house perl scripts [96]. The annotations of Kyoto Encyclopedia of Genes and Genomes (KEGG, http://www.genome.jp/ kegg) pathways were carried out using Blastall software (version: 2.2.23, parameter: default) against the KEGG database [97].

\section{Gene expression analysis}

Using Bowtie, each RNA-seq library was individually aligned to the produced transcriptome assembly [98]. The RSEM package was used for the counting of alignments $[99,100]$. The R Bioconductor package (EdgeR) was adopted to analyze DEGs [101]. The $P$-value established the threshold to test the differential gene expression. The P-value threshold for multiple tests was decided through the false discovery rate (FDR) [102]. The DEGs were selected on the basis of an FDR $\leq 0.05$ and absolute $\log _{2}$ fold change value $\left(\left|\log _{2} F C\right|\right) \geq 1$ [103]. Using the KEGG Orthology Based Annotation System, the DEGs were mapped to the terms in the KEGG database for the pathway enrichment analysis [104]. Significantly enriched pathways related to DEGs were determined using the standard of corrected P-value (Q-value) $\leq 0.05$.

\section{Quantitative RT-PCR (qPCR) analysis}

For verification by qPCR, 11 key candidate genes were chosen based on their important functions associated with drought tolerance and high $\left|\log _{2} \mathrm{FC}\right|$ values (Supplementary Fig. S2). The same RNA samples used for the transcriptome analysis were reverse-transcribed using Power SYBR ${ }^{\circledR}$ Green PCR Master Mix (Thermo Fisher Scientific) with polyT primers. Primer 5 was used to design quantitative primers, which are listed in Supplementary Table S5. GAPDH was used as the internal control [105]. The $20 \mu \mathrm{L}$ reaction mixture contained $10 \mu \mathrm{L}$ of $2 \times$ Talent qPCR PreMix (Tiangen Biotech), $0.3 \mu \mathrm{M}$ of each primer, $50 \mathrm{ng}$ of cDNA as template, and RNase-free $d_{d d} H_{2} \mathrm{O}$, which was added to reach the final volume. qPCR amplification was performed on an ABI stepone Real-Time PCR System (Applied Biosystems, Fostery, CA, USA) using primers listed in Supplementary Table S5. The following PCR conditions were set: $3 \mathrm{~min}$ of preincubation at $95^{\circ} \mathrm{C}$, followed by 40 cycles for $10 \mathrm{~s}$ at $95^{\circ} \mathrm{C}, 20 \mathrm{~s}$ at $59^{\circ} \mathrm{C}, 20 \mathrm{~s}$ at $72^{\circ} \mathrm{C}$, and $5 \mathrm{~s}$ at $75^{\circ} \mathrm{C}$. Then, a DNA melting curve was produced by increasing the heat from 65 to $95^{\circ} \mathrm{C}$ (with a rate of $0.5^{\circ} \mathrm{C}$ and continuous fluorescence measurement) to confirm the specificity of the PCR products. The relative expression level was calculated using the $2^{-\Delta \Delta C t}$ method with three biological replications and three technical replications [106].

\section{Protein expression level analysis}

Important genes were indicated by the relative expression levels of the DEPs. Total proteins were extracted from the fruit bodies using the phenol method [107]. Trypsin [protein:trypsin $=40: 1(\mathrm{w} / \mathrm{w})$ ] was added for enzymolysis, followed by desalination and vacuum drying. The peptide samples were separated using an UltiMate 3000 UHPLC (Thermo Fisher Scientific), ionized 
by a nanoESI source, and then placed into a Q-Ex Active HF tandem mass spectrometer (MS, Thermo Fisher Scientific) for data-independent acquisition mode detection. The spectral library was constructed using the data-independent acquisition of targeted samples. Spectronaut was used to effectively de-convolute, accurately identify, and quantitatively analyze the data [108].

\section{Physiological-biochemical assay}

Melanin was extracted based on a slightly modified version of Liu's method [109]. In short, $1.00 \mathrm{~g}$ of fruit body was fully ground in $50 \mathrm{~mL}$ of $1 \mathrm{M} \mathrm{NaOH}$. The samples were treated in an ultrasonic cleaner $(300 \mathrm{~W})$ for $2 \mathrm{~h}$ at $60^{\circ} \mathrm{C}$. The supernatant $\mathrm{pH}$ was adjusted to 1.5 with $3 \mathrm{M}$ $\mathrm{HCL}$, and the supernatant was immersed in a boiling water bath for $10 \mathrm{~h}$, and then centrifuged at $9156 \mathrm{~g}$ for $15 \mathrm{~min}$. After the precipitation was cooled and dried, the melanin content was calculated.

The assay kits for the measurement of D-mannose (Cas No.: G0583W, Grace, Suzhou, China) content and chitinase (Cas No.: BC0825, Solarbio, Beijing, China) activity were applied in accordance with the manufacturer's instructions.

GA content was detected using a slightly modified version of Deng' s method [110]. In brief, $50.0 \mathrm{mg}$ of fruit body was ground into powder, and dissolved in $500 \mu \mathrm{L}$ acetonitrile $/ \mathrm{H}_{2} \mathrm{O}(90: 10, \mathrm{~V} / \mathrm{V}) .10 \mu \mathrm{L}$ of internal standard mixed solution $(100 \mathrm{ng} / \mathrm{mL})$ was added to the extract as internal standard for quantification. The mixture was rotated for $15 \mathrm{~min}$, and then centrifuged at $12,000 \mathrm{~g}$ for $10 \mathrm{~min}$ at $4{ }^{\circ} \mathrm{C} .10 \mu \mathrm{L}$ of triethylamine and $10 \mu \mathrm{L}$ of 3-bromopropyltrimethylammonium bromide were added to the resulting solution. The reaction solution was rotated, incubated for $1 \mathrm{~h}$ at $90^{\circ} \mathrm{C}$, evaporated to dryness under nitrogen flow, then redissolved in $100 \mu \mathrm{L}$ acetonitrile $/ \mathrm{H}_{2} \mathrm{O}(90: 10, \mathrm{~V} / \mathrm{V})$ and passed through a $0.22 \mu \mathrm{M}$ membrane filter for further LC (liquid chromatography)-MS/MS analysis. The sample extracts were analyzed using an UPLC (Ultra performance liquid chromatography)-MS/MS system (UPLC, ExionLC $^{\mathrm{TM}}$ AD (AB SCIEX, Dublin, CA, USA); MS, Applied Biosystems 6500 Triple Quadrupole (Applied Biosystems). The analytical conditions were as follows: LC: column, Waters ACQUITY UPLC HSS T3 $(100 \mathrm{~mm} \times 2.1 \mathrm{~mm}$ i.d., $1.8 \mu \mathrm{m})$; solvent system, water with $0.04 \%$ acetic acid (A), acetonitrile with $0.04 \%$ acetic acid (B); gradient program, started at 5\% B (0 min), increased to $95 \%$ B (10.0 min), 95\% B (10.1-11.0 min), finally ramped back to $5 \%$ B (11.1 min), $5 \%$ B (11.1$14.0 \mathrm{~min})$; flow rate, $0.35 \mathrm{~mL} / \mathrm{min}$; temperature, $40^{\circ} \mathrm{C}$; and injection volume, $10 \mu \mathrm{L}$.

\section{Data analysis}

The data were analyzed in SPSS 21.0 (IBM Corp., Armonk, NY, USA). Duncan's multiple range test was performed to determine differences between means at a significance level of $p<0.05$, after significant effects were observed during an ANOVA. Pearson's correlation analysis of binary variables was performed, and two variables were considered significantly correlated at $p<0.05$.

\section{Supplementary Information}

The online version contains supplementary material available at https://doi. org/10.1186/s12864-021-08284-9.

Additional file 1.

Additional file 2.

Acknowledgments

We thank International Science Editing (http://www.internationalscienceediti ng.com) for editing this manuscript.

\section{Authors' contributions}

GG and SZ designed the experiments. Material preparation, data collection and analysis were performed by YW, ZY, RY and HG. YW, LS, SZ and GG wrote the manuscript. All authors have read and approved the final manuscript.

\section{Funding}

This work was financially supported by the Science and Technology Program of Guizhou Province (20182330, 20201Z002); and the Major Special Project of Guizhou Province (20193005-5)

Availability of data and materials

All data generated or analyzed for this study are included in this article and its supplementary files. The raw sequence reads were deposited into NCBI SRA database under accession no. PRJNA695780 (https://www.ncbi.nlm.nih.gov/ sra/?term =PRJNA695780)

\section{Declarations}

Ethics approval and consent to participate

Not applicable.

Consent for publication

Not applicable.

\section{Competing interests}

The authors declare that they have no competing interests.

Received: 14 May 2021 Accepted: 28 December 2021

Published online: 15 January 2022

\footnotetext{
References

1. Büntgen U, Egli S, Galván J, Jm D, Aldea J, Latorre J, et al. Droughtinduced changes in the phenology, productivity and diversity of Spanish fungi. Fungal Ecol. 2015;16:6-18. https://doi.org/10.1016/j.funeco. 2015.03.008.

2. Huang D, Ma MG, Wang Q, Zhang MX, Jing GQ, Li C, et al. Arbuscular mycorrhizal fungi enhanced drought resistance in apple by regulating genes in the MAPK pathway. Plant Physiol Biochem. 2020;149:245-55. https://doi.org/10.1016/j.plaphy.2020.02.020.

3. Benjamin JG, Nielsen DC. Water deficit effects on root distribution of soybean, field pea and chickpea. Field Crop Res. 2006;97:248-53. https://doi.org/10.1016/j.fcr.2005.10.005
} 
4. Choudhury S, Panda P, Sahoo L, Panda SK. Reactive oxygen species signaling in plants under abiotic stress. Plant Signal Behav. 2013;8(4):e23681. https://doi.org/10.4161/psb.23681.

5. Das K, Roychoudhury A. Reactive oxygen species (ROS) and response of antioxidants as ROS-scavengers during environmental stress in plants. Front Environ Sci. 2014;2:53. https://doi.org/10.3389/fenvs.2014.00053.

6. Kapoor D, Sharma R, Handa N, Kaur H, Rattan A, Yadav P. Redox homeostasis in plants under abiotic stress: role of electron carriers, energy metabolism mediators and proteinaceous thiols. Front Environ Sci. 2015;3:13. https://doi.org/10.3389/fenvs.2015.00013.

7. Rehman H, Alharby HF, Bamagoos AA, Abdelhamid MT, Rady MM Sequenced application of glutathione as an antioxidant with an organic biostimulant improves physiological and metabolic adaptation to salinity in wheat. Plant Physiol Biochem. 2021;158:43-52. https://doi. org/10.1016/j.plaphy.2020.11.041.

8. Blum A. Osmotic adjustment is a prime drought stress adaptive engine in support of plant production. Plant Cell Environ. 2017;40(1):4-10. https://doi.org/10.1111/pce.12800.

9. Kaya C, Ashraf M, Wijaya L, Ahmad P. The putative role of endogenous nitric oxide in brassinosteroid-induced antioxidant defence system in pepper (Capsicum annuum L.) plants under water stress. Plant Physiol Biochem. 2019;143:119-28. https://doi.org/10.1016/j.plaphy.2019.08. 024.

10. Begum N, Ahanger MA, Su Y, Lei Y, Mustafa NS, Ahmad P, et al. Improved drought tolerance by AMF inoculation in maize (Zea mays) involves physiological and biochemical implications. Plants. 2019;8(12):579. https://doi.org/10.3390/plants8120579.

11. Jain M. Next-generation sequencing technologies for gene expression profiling in plants. Brief Funct Genomic. 2012;11(1):63-70. https://doi. org/10.1093/bfgp/elr038.

12. O'Rourke JA, Bolon Y, Bucciarelli B, Vance CP. Legume genomics: understanding biology through DNA and RNA sequencing. Ann Bot. 2014;113(7):1107-20. https://doi.org/10.1093/aob/mcu072.

13. Varshney RK, Hiremath PJ, Lekha P, Kashiwagi J, Balaji J, Deokar AA, et al. A comprehensive resource of drought and salinity-responsive ESTs for gene discovery and marker development in chickpea (Cicer arietinum L.). BMC Genomics. 2009;10:523. https://doi.org/10.1186/ 1471-2164-10-523.

14. Mantria NL, Fordb R, Coramc TE, Pang EC. Evidence of unique and shared responses to major biotic and abiotic stresses in chickpea. Environ Exp Bot. 2010;69:286-92. https://doi.org/10.1016/j.envexpbot. 2010.05.003.

15. Hiremath PJ, Farmer A, Cannon SB, Woodward J, Kudapa H, Tuteja R, et al. Large-scale transcriptome analysis in chickpea (Cicer arietinum L.), an orphan legume crop of the semi-arid tropics of Asia and Africa. Plant Biotechnol J. 2011;(9):922-31. https://doi.org/10.1111/j.1467-7652.2011. 00625.x.

16. Wang $Y Y$, Zhang $X Y$, Zhou QM, Zhang $X L$, Wei JC. Comparative transcriptome analysis of the lichen-forming fungus Endocarpon pusillum elucidates its drought adaptation mechanisms. Sci China Life Sci. 2015;58(001):89-100. https://doi.org/10.1007/s11427-014-4760-9.

17. Malo ME, Dadachova E. Melanin as an energy transducer and a radioprotector in black fungi. In: Tiquia-Arashiro S, Grube M, editors. Fungi in extreme environments: ecological role and biotechnological significance; 2019. p. 175-84. https://doi.org/10.1007/978-3-030-190309_10.

18. Recchia GH, Konzen ER, Cassieri F, Caldas DG, Tsai SM. Arbuscular mycorrhizal symbiosis leads to differential regulation of drought-responsive genes in tissue-specific root cells of common bean. Front Microbiol. 2018:9:1339. https://doi.org/10.3389/fmicb.2018.01339.

19. Sherameti I, Tripathi $S$, Varma A, Oelmüller R. The root-colonizing endophyte pirifomospora indica confers drought tolerance in Arabidopsis by stimulating the expression of drought stress-related genes in leaves. Mol Plant-Microbe Interact. 2008;21(6):799-807. https://doi.org/10. 1094/MPMI-21-6-0799.

20. Coolen S, Proietti S, Hickman R, Olivas NH, Huang PP, Verk MC, et al. Transcriptome dynamics of Arabidopsis during sequential biotic and abiotic stresses. Plant J. 2016;86(3):249-67. https://doi.org/10.1111/tpj. 13167.

21. Garg R, Shankar R, Thakkar B, Kudapa H, Krishnamurthy L, Mantr N, et al. Transcriptome analyses reveal genotype- and developmental stage-specific molecular responses to drought and salinity stresses in chickpea. Sci Rep. 2016;6(1):19228. https://doi.org/10.1038/srep19228.

22. Wang M, Jiang B, Peng QW, Liu WR, He XM, Liang ZJ, et al. Transcriptome analyses in different cucumber cultivars provide novel insights into drought stress responses. Int J Mol Sci. 2018;19(7):2067. https://doi. org/10.3390/ijms19072067.

23. Zhang ZF, Li YY, Xiao BZ. Comparative transcriptome analysis highlights the crucial roles of photosynthetic system in drought stress adaptation in upland rice. Sci Rep. 2016;6(1):19349. https://doi.org/10.1038/srep1 9349.

24. Shankar R, Bhattacharjee A, Jain M. Transcriptome analysis in different rice cultivars provides novel insights into desiccation and salinity stress responses. Sci Rep. 2016;6:23719. https://doi.org/10.1038/srep23719.

25. Kumar M, Chauhan AS, Kumar M, Yusuf MA, Sanyal I, Chauhan PS. Transcriptome sequencing of chickpea (Cicer arietinum L.) genotypes for identification of drought-responsive genes under drought stress condition. Plant Mol Biol Report. 2019;37:186-203. https://doi.org/10. 1007/s11105-019-01147-4.

26. Zenda T, Liu ST, Wang X, Liu G, Jin HY, Dong AY, et al. Key maize drought-responsive genes and pathways revealed by comparative transcriptome and physiological analyses of contrasting inbred lines. Int J Mol Sci. 2019;20:1268. https://doi.org/10.3390/ijms20061268.

27. Sun XZ, Liu H, Hu SM, Zhou YW, Guan QJ. De novo assembly of Amorpha fruticosa (Amorpha fruticosa L.) transcriptome in response to drought stress provides insight into the tolerance mechanisms. BMC Genomics. 2019;9:396. https://doi.org/10.21203/rs.2.19443/v1.

28. Fan XZ, Zhou Y, Xiao Y, Xu ZY, Bian YB. Cloning, expression and phylogenetic analysis of a divergent laccase multigene family in Auricularia auricula-judae. Microbiol Res. 2014;169(5-6):453-62. https://doi.org/10. 1016/j.micres.2013.08.004

29. Kang MA, Jeon YK, Nam MJ. Auricularia auricula increases an apoptosis in human hepatocellular carcinoma cells via a regulation of the peroxiredoxin1. J Food Biochem. 2020;44:e13373. https://doi.org/10.1111/ jfbc.13373.

30. Li L, Su Y, Feng Y, Hong R. A comparison study on digestion, antiinflammatory and functional properties of polysaccharides from four Auricularia species. Int J Biol Macromol. 2020;154:1074-81. https://doi. org/10.1016/j.ijbiomac.2020.02.324.

31. Xiang H, Sun-Waterhousea DX, Cui C. Hypoglycemic polysaccharides from Auricularia auricula and Auricularia polytricha inhibit oxidative stress, NF-KB signaling and proinflammatory cytokine production in streptozotocin-induced diabetic mice. Food Sci Human Wellness. 2021;10:87-93. https://doi.org/10.1016/j.fshw.2020.06.001.

32. Huang XJ, Nie SP. The structure of mushroom polysaccharides and their beneficial role in health. Food Funct. 2015;6:3205-17. https://doi.org/ 10.1039/c5fo00678c.

33. Miao JN, Regenstein JM, Qiu JQ, Zhang JQ, Zhang XP, Li HX. Isolation, structural characterization and bioactivities of polysaccharides and its derivatives from Auricularia-a review. Int J Biol Macromol. 2020;150:10213. https://doi.org/10.1016/j.jibiomac.2020.02.054.

34. Ma HL, Xu XH, Feng LJ. Responses of antioxidant defenses and membrane damage to drought stress in fruit bodies of Auricularia auriculajudae. World J Microbiol Biotechnol. 2014;30:119-24. https://doi.org/10. 1007/s11274-013-1416-z.

35. Wu F, Yuan Y, He SH, Bandara AR, Hyde KD, Malysheva VF, et al. Global diversity and taxonomy of the Auricularia auricula-judae complex (Auriculariales, Basidiomycota). Mycol Prog. 2015;14(10):95. https://doi. org/10.1007/s11557-015-1113-4.

36. Ma ZC, Wang JG, Zhang LN, Zhang YF, Ding K. Evaluation of water soluble $\beta$-d-glucan from Auricularia auricular-judae as potential anti-tumor agent. Carbohydr Polym. 2010;80(3):977-83. https://doi.org/10.1016/j. carbpol.2010.01.015.

37. Bai HN, Wang ZY, Cui J, Yun KL, Zhang H, Liu RH, et al. Synergistic radiation protective effect of purified Auricularia auricular-judae polysaccharide (AAP IV) with grape seed procyanidins. Molecules. 2014;19:2067594. https://doi.org/10.3390/molecules 191220675.

38. Li XL, Yan LJ, Li Q, Tan H, Zhou J, Miao RY, et al. Transcriptional profiling of Auricularia cornea in selenium accumulation. Sci Rep. 2019;9(1):5641. https://doi.org/10.1038/s41598-019-42157-2.

39. Chen L, Sun H, Wang FJ, Yue DD, Shen XK, Sun WN, et al. Genome-wide identification of MAPK cascade genes reveals the 
GhMAP3K14-GhMKK11-GhMPK31 pathway is involved in the drought response in cotton. Plant Mol Biol. 2020;103:211-23. https://doi.org/10. 1007/s11103-020-00986-0.

40. Gu JY, Li QW, Liu J, Ye ZD, Feng T, Wang G, et al. Ultrasonic-assisted extraction of polysaccharides from Auricularia auricula and effects of its acid hydrolysate on the biological function of Caenorhabditis elegans. Int J Biol Macromol. 2021;167:423-33. https://doi.org/10.1016/j.jibio mac.2020.11.160.

41. Li JW, Li ZW, Zhao T, Yan XF, Pang QY. Proteomic analysis of Auricularia auricula-judae under freezing treatment revealed proteins and pathways associated with melanin reduction. Front Microbiol. 2021;11:610173. https://doi.org/10.3389/fmicb.2020.610173.

42. Langfelder K, Streibel M, Jahn B, Haase G, Brakhage AA. Biosynthesis of fungal melanins and their importance for human pathogenic fungi. Fungal Genet Biol. 2003;38:143-58. https://doi.org/10.1016/S10871845(02)00526-1.

43. Zhao SY, Zeng WH, Li Z, Peng Y. Mannose regulates water balance, leaf senescence, and genes related to stress tolerance in white clover under osmotic stress. Biol Plant. 2020;64:406-16. https://doi.org/10.32615/bp. 2020.017.

44. Forgac M. S1/7 structure, function and regulation of the vacuolar ATPases. Biochim Biophys Acta. 2008;1777:S10. https://doi.org/10. 1016/j.bbabio.2008.05.045.

45. Adams DJ. Fungal cell wall chitinases and glucanases. Microbiology. 2004;150:2029-35. https://doi.org/10.1099/mic.0.26980-0.

46. Ramos-Ruiz R, Martinez F, Knauf-Beiter G. The effects of GABA in plants. Cogent Food Agric. 2019;5(1):1670553. https://doi.org/10.1080/23311 932.2019.1670553.

47. Araújo WL, Ishizaki K, Nunes-Nesi A, Larson TR, Tohge T, Krahnert I, et al. Identification of the 2-hydroxyglutarate and isovaleryl-CoA dehydrogenases as alternative electron donors linking lysine catabolism to the electron transport chain of Arabidopsis mitochondria. Plant Cell. 2010;22(5):1549-63. https://doi.org/10.1105/tpc.110.075630.

48. Yuan Y, Wu F, Si J, Zhao YF, Dai YC. Whole genome sequence of Auricularia heimuer (Basidiomycota, Fungi), the third most important cultivated mushroom worldwide. Genomics. 2019;111:50-8. https://doi. org/10.1016/j.ygeno.2017.12.013.

49. Planchet E, Limami AM, D'Mello JP. Amino acid synthesis under abiotic stress. CAB Int. 2015. https://doi.org/10.1079/9781780642635.0262.

50. Zhang XQ, Zhao YZ, Wang SJ. Responses of antioxidant defense system of epilithic mosses to drought stress in karst rock desertified areas. Acta Geochim. 2017;36(2):205-12. https://doi.org/10.1007/ s11631-017-0140-z.

51. Liberti D, Alfieri ML, Monti DM, Panzella L, Napolitano A. A melaninrelated phenolic polymer with potent photoprotective and antioxidant activities for dermo-cosmetic applications. Antioxidants. 2020;9:270. https://doi.org/10.3390/antiox9040270.

52. Jiang H, Liu GL, Chi Z, Hu Z, Chi ZM. Genetics of trehalose biosynthesis in desert-derived Aureobasidium melanogenum and role of trehalose in the adaptation of the yeast to extreme environments. Curr Genet. 2018;64:479-91. https://doi.org/10.1007/s00294-017-0762-z.

53. Wang MZ, Danesi P, James TY, Al-Hatmi AM, Najafzadeh MJ, Dolatabadi $S$, et al. Comparative pathogenicity of opportunistic black yeasts in Aureobasidium. Mycoses. 2019;62(9):803-11. https://doi.org/10.1111/ myc.12931.

54. Pihet M, Vandeputte P, Tronchin G, Renier G, Saulnier P, Georgeault S, et al. Melanin is an essential component for the integrity of the cell wall of Aspergillus fumigatus conidia. BMC Microbiol. 2009;9:177. https://doi. org/10.1186/1471-2180-9-177.

55. Ito S, Wakamatsu K. Chemistry of mixed melanogenesis-pivotal roles of dopaquinone. Photochem Photobiol. 2008;84:582-92. https://doi.org/ 10.1111/j.1751-1097.2007.00238.x.

56. Gonyar LA, Fankhauser SC, Goldberg JB. Single amino acid substitution in homogentisate 1,2-dioxygenase is responsible for pigmentation in a subset of Burkholderia cepacia complex isolates. Environ Microbiol Rep. 2015;7(2):180-7. https://doi.org/10.1111/1758-2229.12217.

57. Zhao EH, Ergul B, Zhao W. Caffeine's antioxidant potency optically sensed with double-stranded DNA-encased single-walled carbon nanotubes. J Phys Chem B. 2015;119:4068-75. https://doi.org/10.1021/ acs.jpcb.5b00708.
58. Vieira AJ, Gaspar EM, Santos PM. Mechanisms of potential antioxidant activity of caffeine. Radiat Phys Chem. 2020;174:108968. https://doi.org/ 10.1016/.j.radphyschem.2020.108968.

59. Dhindsa RS. Drought stress, enzymes of glutathione metabolism, oxidation injury, and protein synthesis in Tortula ruralis. Plant Physiol. 1991;95(2):648-51. https://doi.org/10.1104/pp.95.2.648.

60. Ahmed A, Shamsi A, Shahwan MJ, Amin F, Bano B. Role of phytocystatin in combating metal ion induced conformational alterations in glutathione reductase. Int J Biol Macromol. 2019;127:271-7. https://doi. org/10.1016/j.ijbiomac.2019.01.055.

61. Roze LV, Laivenieks M, Hong SY, Wee J, Wong SS, Vanos B, et al. Aflatoxin biosynthesis is a novel source of reactive oxygen species-a potential redox signal to initiate resistance to oxidative stress? Toxins. 2015;7(5):1411-30. https://doi.org/10.3390/toxins7051411.

62. Verbruggen $\mathrm{N}$, Hermans $C$. Proline accumulation in plants: a review. Amino Acids. 2008;35:753-9. https://doi.org/10.1007/ s00726-008-0061-6.

63. Yaakop AS, Chan KG, Ee R, Lim YL, Lee SK, Manan FA, et al. Characterization of the mechanism of prolonged adaptation to osmotic stress of Jeotgalibacillus malaysiensis via genome and transcriptome sequencing analyses. Sci Rep. 2016;6:33660. https://doi.org/10.1038/srep33660.

64. Sarid S, Berger A, Katchalski E. Proline iminopeptidase. J Biol Chem. 1959;234(7):1740-6. https://doi.org/10.1002/jbmte.390010408.

65. Bremer E, Krämer R. Responses of microorganisms to osmotic stress. Annu Rev Microbiol. 2019;73:313-34. https://doi.org/10.1146/annur ev-micro-020518-115504.

66. Vermassen A, Dordet-Frisoni E, Foye AD, Micheau P, Laroute V, Leroy $\mathrm{S}$, et al. Adaptation of staphylococcus xylosus to nutrients and osmotic stress in a salted meat model. Front Microbiol. 2016;7:87. https://doi. org/10.3389/fmicb.2016.00087.

67. Dever TE, Dinman JD, Green R. Translation elongation and recoding in eukaryotes. Cold Spring Harb Perspect Biol. 2018;10:a032649. https:// doi.org/10.1101/cshperspect.a032649.

68. Proud CG. Phosphorylation and signal transduction pathways in translational control. Cold Spring Harb Perspect Biol. 2018;1 1:a0330501. https://doi.org/10.1101/cshperspect.a033050.

69. Silva GM, Finley D, Vogel C. K63 polyubiquitination is a new modulator of the oxidative stress response. Nat Struct Mol Biol. 2015;22(2):116-23. https://doi.org/10.1038/nsmb.2955.

70. Simsek D, Barna M. An emerging role for the ribosome as a nexus for post-translational modifications. Curr Opin Cell Biol. 2017;45:92-101. https://doi.org/10.1016/j.ceb.2017.02.010.

71. Lim JJ, Grinstein S, Roth Z. Diversity and versatility of phagocytosis: roles in innate immunity, tissue remodeling, and homeostasis. Front Cell Infect Microbiol. 2017;7:191. https://doi.org/10.3389/fcimb.2017.00191.

72. Ma J, Zhang Y, Wang HG, Zhen WC, Zhang YC, Duan HJ, et al. Differentially expressed genes and enriched pathways during drought-sensitive period under field conditions in bread wheat. Plant Mol Biol Report. 2019;37:389-400. https://doi.org/10.1007/s11105-019-01163-4.

73. Wang GS, Nauseef WM. Salt, chloride, bleach, and innate host defense. J Leukoc Biol. 2015:98:163-72. https://doi.org/10.1189/jlb.4UR0315-109R.

74. MartínezSoto D, RuizHerrera J. Functional analysis of the MAPK pathways in fungi. Rev Iberoam Micol. 2017:34(4):192-202. https://doi.org/ 10.1016/j.riam.2017.02.006.

75. Silva LP, Castro PA, Reis TF, Paziani MH, Kress MR, Riaño-Pachón DM, et al. Genome-wide transcriptome analysis of Aspergillus fumigatus exposed to osmotic stress reveals regulators of osmotic and cell wall stresses that are SakA ${ }^{\mathrm{HOG} 1}$ and MpkC dependent. Cell Microbiol. 2017;19:e12681. https://doi.org/10.1111/cmi.12681.

76. Wang C, Lu WJ, He XW, Wang F, Zhou YL, Guo XL, et al. The cotton mitogen-activated protein kinase kinase 3 functions in drought tolerance by regulating stomatal responses and root growth. Plant Cell Physiol. 2016;57(8):1629-42. https://doi.org/10.1093/pcp/pcw090.

77. Yao HY, Xue HW. Phosphatidic acid (PA) plays key roles regulating plant development and stress responses. J Integr Plant Biol. 2018;60(9):85163. https://doi.org/10.1111/jipb.1265.

78. Kamerewerd J, Zadra I, Kürnsteiner H, Kück U. PcchiB1, encoding a class $\checkmark$ chitinase, is affected by PcVelA and PcLaeA, and is responsible for cell wall integrity in Penicillium chrysogenum. Microbiology. 2011;157:303648. https://doi.org/10.1099/mic.0.051896-0. 
79. Zhou JS, Kang LQ, Liu CC, Niu X, Wang XJ, Liu HL, et al. Chitinases play a key role in the stipe cell wall extension in the mushroom Coprinopsis cinerea. Appl Environ Microbiol. 2019;85(15):e00532-19. https://doi.org/ 10.1128/AEM.00532-19.

80. Schlumbaum A, Mauch F, Vögeli U, Boller T. Plant chitinases are potent inhibitors of fungal growth. Nature. 1986;324:365-7. https://doi.org/10. 1038/324365a0.

81. Zhu JK. Salt and drought stress signal transduction in plants. Annu Rev Plant Biol. 2002;53:247-73. https://doi.org/10.1146/annurev.arplant.53. 091401.143329.

82. Kumar S, Punekar NS. The metabolism of 4-aminobutyrate (GABA) in fungi. Mycol Res. 1997;101:403-9. https://doi.org/10.1017/S095375629 6002742.

83. Podlešáková K, Ugena L, Spíchal L, Doležal K, Diego ND. Phytohormones and polyamines regulate plant stress responses by altering GABA pathway. New Biotechnol. 2019;48:53-65. https://doi.org/10. 1016/j.nbt.2018.07.003.

84. Fan LQ, Wu XL, Tian Z, Jia KZ, Pan YH, Li JR, et al. Comparative proteomic analysis of $\mathrm{Y}$-aminobutyric acid responses in hypoxia-treated and untreated melon roots. Phytochemistry. 2015;116:28-37. https://doi. org/10.1016/j.phytochem.2015.02.023.

85. Hu XH, Xu ZR, Xu WN, Li JM, Zhao N, Zhou Y. Application of $\gamma$-aminobutyric acid demonstrates a protective role of polyamine and GABA metabolism in muskmelon seedlings under $\mathrm{Ca}\left(\mathrm{NO}_{3}\right)_{2}$ stress. Plant Physiol Biochem. 2015;92:1-10. https://doi.org/10.1016/j.plaphy.2015. 04.006.

86. Mead O, Thynne E, Winterberg B, Solomon PS. Characterising the role of GABA and its metabolism in the wheat pathogen Stagonospora nodorum. PLoS ONE. 2013;8(11):e78368. https://doi.org/10.1371/journal. pone. 0078368 .

87. Engqvist M, Drincovich MF, Flúgge U, Maurino VG. Two D-2-hydroxyacid dehydrogenases in Arabidopsis thaliana with catalytic capacities to participate in the last reactions of the methylglyoxal and beta-oxidation pathways. J Biol Chem. 2009;284(37):25026-37. https://doi.org/10.1074/ jbc.M109.021253.

88. Schertl P, Cabassa C, Saadallah K, Bordenave M, Savour A, Braun H. Biochemical characterization of proline dehydrogenase in Arabidopsis mitochondria. FEBS J. 2014;281:2794-804. https://doi.org/10.1111/febs. 12821.

89. Hildebrandt TM, Nesi AN, Araújo WL, Braun HR. Amino acid catabolism in plants. Mol Plant. 2015;8:1563-79. https://doi.org/10.1016/j.molp. 2015.09.005.

90. Veneziani RC, Ambrósio SR, Martins CH, Lemes DC, Oliveira LC. Antibacterial potential of diterpenoids. Stud Nat Prod Chem. 2017:54:109-39. https://doi.org/10.1016/B978-0-444-63929-5.00004-8.

91. Chen YX, Chen YS, Shi CM, Huang ZB, Zhang Y, Li SK, et al. SOAPnuke: a MapReduce acceleration-supported software for integrated quality control and preprocessing of high-throughput sequencing data. GigaScience. 2018;7:1-6. https://doi.org/10.1093/gigascience/gix120.

92. Bolger AM, Lohse M, Usadel B. Trimmomatic: a flexible trimmer for Illumina sequence data. Bioinformatics. 2014;30(15):2114-20. https:// doi.org/10.1093/bioinformatics/btu170f.

93. Grabherr MG, Haas BJ, Yassour M, Levin JZ, Thompson DA, Amit I, et al. Trinity: reconstructing a full-length transcriptome without a genome from RNA-Seq data. Nat Biotechnol. 2013;29(7):644-52. https://doi.org/ 10.1038/nbt.1883.

94. Pruitt KD, Tatusova T, Maglott DR. NCBI reference sequences (RefSeq): a curated non-redundant sequence database of genomes, transcripts and proteins. Nucleic Acids Res. 2007;35:61-5. https://doi.org/10.1093/ nar/gkl842.

95. Conesa A, Götz S, García-Gómez JM, Terol J, Talón M, Robles M. Blast2GO: a universal tool for annotation, visualization and analysis in functional genomics research. Bioinformatics. 2005;21(18):3674-6. https://doi.org/10.1093/bioinformatics/bti610.

96. Ashburner M, Ball CA, Blake JA, Botstein D, Butler H, Cherry JM, et al. Gene ontology: tool for the unification of biology. Nat Genet. 2000;25(1):25-9. https://doi.org/10.1038/75556.

97. Kanehisa M, Goto S, Sato Y, Furumichi M, Tanabe M. KEGG for integration and interpretation of large-scale molecular data sets. Nucleic Acids Res. 2012;40:D109-14. https://doi.org/10.1093/nar/gkr988.
98. Langmead B, Trapnell C, Pop M, Salzberg SL. Ultrafast and memoryefficient alignment of short DNA sequences to the human genome. Genome Biol. 2009;10(3):R25. https://doi.org/10.1186/gb-2009-10-3-r25.

99. Langmead B, Salzberg SL. Fast gapped-read alignment with bowtie 2 . Nat Methods. 2012;9(4):357-9. https://doi.org/10.1038/nmeth.1923.

100. Li B, Dewey CN. RSEM: accurate transcript quantification from RNAseq data with or without a reference genome. BMC Bioinformatics. 2011;12:323. https://doi.org/10.1186/1471-2105-12-323.

101. Robinson MD, McCarthy DJ, Smyth GK. EdgeR: a bioconductor package for differential expression analysis of digital gene expression data. Bioinformatics. 2010;26(1):139-40. https://doi.org/10.1093/bioinforma tics/btp616.

102. Benjamini $Y$, Yekutieli $D$. The control of the false discovery rate in multiple testing under dependency. Ann Stat. 2001;29:1165-88. https://doi. org/10.1214/aos/1013699998.

103. Wang LK, Feng ZX, Wang X, Wang XW, Zhang XG. DEGseq: an R package for identifying differential expressed genes from RNA-seq data. Bioinformatics. 2010;26(1):136-8. https://doi.org/10.1093/bioinforma tics/btp612.

104. Xie C, Mao XZ, Huang JJ, Ding Y, Wu JM, Dong S, et al. KOBAS 2.0: a web server for annotation and identification of enriched pathways and diseases. Nucleic Acids Res. 2011;39(Suppl 2):316-22. https://doi.org/10 1093/nar/gkr483.

105. Zou L, Sun TT, Yang YY, Zhang LF, Zhang J. Molecular characterization of a glycoside hydrolase family-51 a-L-arabinofuranosidase from Auricularia auricula. Biotechnol Biotechnol Equip. 2017;31(3):469-76. https:// doi.org/10.1080/13102818.2017.1286233.

106. Depuydt S, Hardtke CS. Hormone signaling crosstalk in plant growth regulation. Curr Biol. 2011;21(9):R365-73. https://doi.org/10.1016/j.cub. 2011.03.013.

107. Isaacson T, Damasceno CM, Saravanan RS, He YH, Catalá C, Saladié M, et al. Sample extraction techniques for enhanced proteomic analysis of plant tissues. Nat Protoc. 2006;1:769-74. https://doi.org/10.1038/nprot. 2006.102.

108. Bernhardt OM, Selevsek N, Gillet LC, Rinner O, Picotti P, Aebersold R, et al. Spectronaut: a fast and efficient algorithm for MRM-like processing of data independent acquisition (SWATH-MS) data. 60th American Society for Mass Spectometry Conference. 2014.

109. Liu X, Hou RL, Huang YP, Xu KQ, Wu XP, Lin WX, et al. Physicochemical properties and the extraction process of natural melanin from Auricularia polytricha. SDRP J Food Sci Technol. 2019;4(1):539-52. https://doi. org/10.25177/JFST.4.1.2.

110. Deng T, Wu DP, Duan CF, Yan XH, Du Y, Zou J, et al. Spatial profiling of gibberellins in a single leaf based on microscale matrix solid-phase dispersion and precolumn derivatization coupled with ultraperformance liquid chromatography-tandem mass spectrometry. Anal Chem. 2017;89:9537-43. https://doi.org/10.1021/acs.analchem.7b02589.

\section{Publisher's Note}

Springer Nature remains neutral with regard to jurisdictional claims in published maps and institutional affiliations.

Ready to submit your research? Choose BMC and benefit from:

- fast, convenient online submission

- thorough peer review by experienced researchers in your field

- rapid publication on acceptance

- support for research data, including large and complex data types

- gold Open Access which fosters wider collaboration and increased citations

- maximum visibility for your research: over $100 \mathrm{M}$ website views per year

At BMC, research is always in progress.

Learn more biomedcentral.com/submissions 